\title{
Community Stroke Rehabilitation: How Do Rural Residents Fare Compared With Their Urban Counterparts?
}

\author{
Laura Allen, Amanda McIntyre, Shannon Janzen, Marina Richardson, \\ Matthew Meyer, David Ure, Robert Teasell
}

\begin{abstract}
Background: Rural living has been demonstrated to have an effect on a person's overall health status, and rural residing individuals often have decreased access to health and specialized rehabilitation services. Aim: The aim of this study was to determine if there are differences in recovery from stroke between urban and rural-dwelling stroke survivors accessing an in-home, community-based, interdisciplinary, stroke rehabilitation program. Methods: Data from a cohort of 1222 stroke survivors receiving care from the Community Stroke Rehabilitation Teams between January 2009 and June 2013 was analyzed. This program delivers stroke rehabilitation care directly in a person's home and community. Functional and psychosocial outcomes were evaluated at baseline, discharge, and six -month follow-up. A series of multiple linear regression analyses was performed to determine if rural versus urban status was a significant predictor of discharge and 6-month health outcomes. Results: The mean age of the rural cohort was $68.8( \pm 13.1)$ years $(53.6 \%$ male), and the urban cohort was 68.4 $( \pm 13.0)$ years $(44.8 \%$ male). A total of $278(35.4 \%)$ individuals were classified as living in a rural area using the Rurality Index for Ontario. In multivariate linear regression analysis, no significant differences on the Functional Independence Measure, the Stroke Impact Scale, the Hospital Anxiety and Depression Scale, or the Reintegration to Normal Living Index were found between urban and rural cohorts. Conclusions: When provided with access to a home-based, specialized stroke rehabilitation program, rural dwelling stroke survivors make and maintain functional gains comparable to their urban-living counterparts.
\end{abstract}

RÉSUMÉ: Réadaptation dans la communauté après un accident vasculaire cérébral: comment les patients résidant en milieu rural se portent-ils par rapport aux patients résidant en milieu urbain? Contexte: Il a été démontré que le fait de vivre en milieu rural a un effet sur la santé globale et que les individus résidant en milieu rural ont souvent moins accès à des services de santé et à des services de réadaptation spécialisés que ceux qui vivent en milieu urbain. Objectif: Le but de l'étude était de déterminer s'il existe des différences dans la récupération suite à un accident vasculaire cérébral (AVC) entre les survivants résidant en milieu urbain et ceux du milieu rural qui ont accès à un programme interdisciplinaire de réadaptation de l'AVC à domicile, dans la communauté. Méthode: Nous avons analysé les données d'une cohorte de 1222 survivants d'un AVC recevant des soins d'équipes de réadaptation de l'AVC dans la communauté entre janvier 2009 et juin 2013. Ce programme fournit des soins de réadaptation dans la communauté après un AVC, directement au domicile de l'individu. Les résultats fonctionnels et psychosociaux ont évalués initialement, au moment du congé hospitalier et six mois plus tard. Nous avons analysé les données au moyen de l'analyse de régression linéaire afin de déterminer si la résidence en milieu rural par rapport à un milieu urbain était un facteur de prédiction significatif des résultats sur la santé au moment du congé hospitalier et six mois plus tard. Résultats: L'âge moyen de la cohorte de patients vivant en milieu rural était de 68,8 ans ( $\pm 13,1$ ans), dont 53,6\% étaient des hommes, par rapport à 68,4 ans ( \pm 13,0 ans) et 44,8\% d'hommes pour la cohorte urbaine. En tout, 278 individus (35,4\%) étaient classifiés comme vivant dans une zone rurale selon le Rurality Index for Ontario. À l'analyse de régression linéaire multivariée, il n'existait pas de différence significative entre la cohorte urbaine et la cohorte rurale selon les échelles d'évaluation suivantes: la Mesure de l'indépendance fonctionnelle, la Stroke Impact Scale, la Hosptal Anxiety and Depression Scale ou la Reintegration to Normal Living Index. Conclusions: Quand les survivants à un AVC qui vivent en milieu rural ont accès à un programme de réadaptation à domicile spécialisé en $\mathrm{AVC}$, ils obtiennent et maintiennent des gains fonctionnels comparables à ceux qui vivent en milieu urbain.

Keywords: Community, Stroke, Rehabilitation, Rural

doi:10.1017/cjn.2015.324

Can J Neurol Sci. 2016; 43: 98-104

More than 50,000 individuals in Canada experience a stroke every year, and an estimated 315,000 Canadians are currently living with the prolonged consequences of stroke. ${ }^{1}$ More than $60 \%$ of stroke survivors have physical deficits requiring some degree of physical therapy, ${ }^{2}$ and approximately $40 \%$ have persisting cognitive deficits. ${ }^{3}$ Following acute care, stroke survivors are often discharged to inpatient rehabilitation where the aim is to maximize physical, psychosocial, and cognitive recovery. ${ }^{4}$

From the Lawson Health Research Institute, London, Ontario (LA, AM, SJ, MR, MM, RT); St. Joseph's Health Care, London, Ontario (DU, RT); Schulich School of Medicine and Dentistry, Western University (DU), London, Ontario.

Received December 6, 2014. Final Revisions Submitted August 19, 2015.

Correspondence to: Laura Allen, Parkwood Institute, 550 Wellington Rd., London, Ontario, N6C 0A7. Email:laura.allen@ sjhc.london.on.ca 
Despite the progress made during inpatient rehabilitation, approximately $33 \%$ of stroke survivors will still have deficits requiring additional rehabilitation in the community. ${ }^{5}$

The inability to access health care services may impede a patient's recovery and consequently result in an increased risk of medical complications, depression, cognitive difficulties, and decreased quality of life. ${ }^{4,6}$ It has been shown that individuals residing in rural settings often have poorer access to health care, especially rehabilitation services, poststroke. ${ }^{7-9}$ Given these inequalities, it is presumed that recovery poststroke may differ between rural and urban residing individuals; however, there is inadequate research examining such a relationship. What it means to live in a rural area also varies according to geographical region. ${ }^{7}$ In Canada, the criteria for an urban area includes a population of at least 1000 and a density of at least 400 people per square kilometre, with the remaining area defined as rural. ${ }^{10}$ By this definition, approximately $19 \%$ to $30 \%$ of Canadians live in rural areas. ${ }^{11}$

Ontario, Canada's most densely populated province, is divided into 14 Local Health Integration Networks (LHINs). The southwest LHIN (Figure 1) serves nearly 1 million people in an area of 21,639 square kilometers. It consists of eight counties; the southern four counties are the most densely populated and are home to half the region's population, many of whom reside in London, a city with 350,000 residents. The northern and middle four counties are almost entirely rural with many small towns and only two small cities. ${ }^{12}$

A potential solution for improving access to rehabilitation services for rural stroke survivors is home-based rehabilitation. The Community Stroke Rehabilitation Teams (CSRTs) in the southwest LHIN are one such example of a home-based rehabilitation program that provides coordinated personalized support and therapeutic services to clients recovering from stroke in both urban and rural locations. The objective of this study was to compare the gains between urban and rural residents who received specialized multidisciplinary stroke rehabilitation services from CSRTs.

\section{MeTHODS}

The CSRTs provide interdisciplinary, individualized services to any stroke survivor with ongoing rehabilitation needs and consist of a physiotherapist, occupational therapist, speech language pathologist, social worker, registered nurse, therapeutic recreation specialist, and rehabilitation therapist. Clients accessing the CSRT program are individuals for whom traditional outpatient stroke rehabilitation following hospital discharge is either unavailable or inaccessible. Individuals may enter the program at any time poststroke and receive visits based on individual need (both therapy type and frequency). Individual therapists travel to a client's home to provide therapy. Team rounds are held weekly to discuss client rehabilitation goals.

This study was granted ethics approval by the Western University Research Ethics Board.

\section{Dataset}

Data were obtained from the CSRT central administrative database. Data were collected on CSRT clients between January 2009 and June $2013(\mathrm{~N}=1222)$. Client demographic information collected on admission to the CSRT program included age, gender, postal code, marital status, and date and type of stroke. CSRT service information included date of client referral, date of first CSRT team visit, and date of discharge from active services. All visits where therapy was provided by a physiotherapist, occupational therapist, speech language pathologist, social worker, registered nurse, therapeutic recreation specialist, or rehabilitation therapist were recorded by date.

\section{Outcomes}

Outcomes were assessed on admission to, and discharge from, the CSRT program with a follow-up assessment completed within 6 months postdischarge. All outcome measures were administered by a member of the CSRTs. Assessments captured functional and psychosocial outcomes. The Functional Independence Measure $(\mathrm{FIM})^{13}$ and either the Stroke Impact Scale ${ }^{14}$ or the Reintegration to Normal Living Index (RNLI) ${ }^{15}$ were used to assess functional outcomes. The Stroke Impact Scale was assessed by CSRT staff from January 2009 to October 2012, but was replaced with the RNLI in May 2012. Client's psychosocial status was assessed using the Hospital Anxiety and Depression Scale (HADS) ${ }^{16}$ until January 2011, when it was replaced by the Patient Health Questionnaire-9. For further detail regarding methodology and outcome measures, please refer to Allen et al. ${ }^{17}$

\section{Inclusion Criteria and Rurality}

To be included in this study, clients in the dataset had to have satisfied four inclusion criteria: (1) demographic information available; (2) at least one baseline outcome measure completed; (3) active therapy received; and (4) at least one discharge or follow-up outcome measure completed. Active therapy was defined as a client receiving a minimum of four visits from any one discipline. Individuals were assigned a Rurality Index for Ontario score generated using the client's six-digit postal code. The Rurality Index for Ontario score provides an indication of the degree of rurality of residence on a continuous scale (0 to 100), with scores greater than or equal to 40 indicating a rural residence. ${ }^{18}$ Each postal code was individually entered into the Ontario Medical Association's Rurality Index for Ontario Postal Code Look Up tool bar. ${ }^{18}$ Rurality of the client's residence was the main variable of interest in this study.

\section{Data Analysis}

Rehabilitation intensity was measured by the number of visits a client received from each health care discipline as well as the average number of visits received per week in the program. Descriptive analysis, using means with standard deviations and frequencies where appropriate, were completed to describe both rural- and urban-dwelling cohorts. Independent t-tests and chi-squared tests were conducted to examine similarities in baseline demographic (age, sex, stroke type, marital status, weeks since stroke) and CSRT service delivery characteristics (i.e. wait time, number of visits, length of stay in the program) between the two populations.

Mean changes in outcome measures scores between admission and discharge, and discharge and follow-up, were also calculated for both rural and urban populations. Significant between-group differences were tested using independent t-tests in an unadjusted analysis.

A series of multiple linear regression analyses was completed to assess the relationship between a client's rurality of residence and change in functional and psychosocial outcomes over time. The dependent variable for each regression analysis was the 


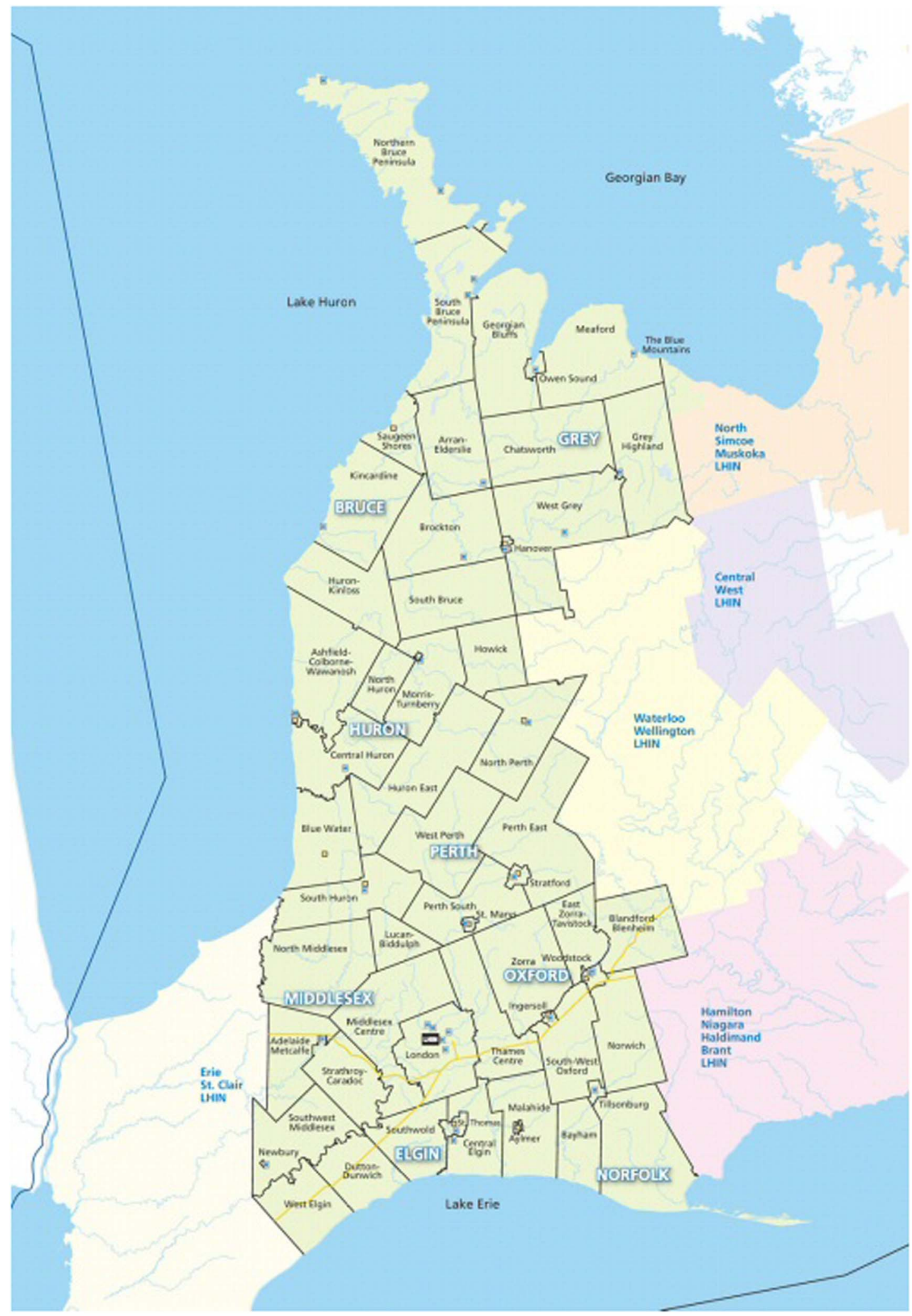

Figure 1: Map of the southwest local health integration network. ${ }^{25}$

mean change in outcome score from admission to discharge, and discharge to follow-up. To isolate the effects of rurality of residence on client outcomes, the independent variables of interest were entered into the analysis in two steps. The first step included age and admission FIM score as well as service and demographic characteristics considered conceptually appropriate 


\section{Table 1: Demographic and CSRT service-related variables}

\begin{tabular}{|c|c|c|c|}
\hline Variable & Urban & Rural & p value \\
\hline No. of individuals (\%) & $508(64.6)$ & $278(35.4)$ & - \\
\hline Mean age (SD), years & $68.4(13.0)$ & $68.8(13.1)$ & 0.666 \\
\hline No. of males (\%) & $227(44.8)$ & $281(53.6)$ & 0.780 \\
\hline Marital status (\%) & & & 0.413 \\
\hline Single & 8.4 & 5.9 & \\
\hline Married & 61.3 & 66.7 & \\
\hline Common law & 5.6 & 7.1 & \\
\hline Divorced & 4.9 & 3.1 & \\
\hline Widowed & 18.3 & 15.3 & \\
\hline Separated & 1.5 & 2.0 & \\
\hline Time poststroke, weeks & $16.5(36.0)$ & $20.5(49.6)$ & 0.204 \\
\hline Stroke type (\% ischemic) & 72.8 & 73.4 & 0.842 \\
\hline No. of visits: TRS & $3.2(4.7)$ & $4.7(5.4)$ & 0.003 \\
\hline No. of visits: PT & $4.3(5.7)$ & $7.0(9.2)$ & 0.000 \\
\hline No. of visits: OT & $4.8(4.5)$ & $6.4(8.4)$ & 0.009 \\
\hline No. of visits: SLP & $3.3(5.3)$ & $2.7(6.0)$ & 0.282 \\
\hline No. of visits: RN & $4.3(3.6)$ & $4.5(3.8)$ & 0.673 \\
\hline No. of visits: RT & $9.6(10.0)$ & $12.8(16.1)$ & 0.010 \\
\hline No. of visits: SW & $2.1(3.1)$ & $2.1(3.8)$ & 0.859 \\
\hline No. of visits, total & $31.6(23.3)$ & $40.0(34.0)$ & 0.002 \\
\hline No. of visits/ week & $2.2(1.6)$ & $2.4(1.9)$ & 0.182 \\
\hline Wait time in days & $11.0(7.6)$ & $7.7(9.1)$ & 0.000 \\
\hline Length of stay, days & $115.8(75.2)$ & $138.7(91.0)$ & 0.000 \\
\hline
\end{tabular}

CSRT $=$ Community Stroke Rehabilitation Team; OT = occupational therapist $\mathrm{PT}=$ physiotherapist $\mathrm{RN}=$ registered nurse RT $=$ rehabilitation therapist; $\mathrm{SD}=$ standard deviation; $\mathrm{TRS}=$ therapeutic recreation specialist; $\mathrm{SLP}=$ speech language pathologist; $\mathrm{SW}=$ social worker.

to the particular outcome of interest. The second step included the binary rural/urban variable. The change in the amount of variance explained by the model $\left(R^{2}\right)$ after the addition of the rurality variable was assessed for significance $(\mathrm{p}<0.05)$. To account for multiple comparisons, a Bonferroni corrected level of statistical significance was defined as $\mathrm{p}<0.003$ (95\% confidence interval [CI]). All analyses were completed using SPSS, v.21.0.

\section{RESUlTS}

A total of 786 clients $(64 \%)$ of a possible 1222 met the inclusion criteria for this study. Table 1 describes the demographic and program characteristics of both the urban and rural cohorts. No statistically significant differences were observed between the two groups for any of the baseline demographic characteristics. There were significant differences between the groups with respect to amount of services provided by the CSRT. Rural residing individuals received significantly more visits overall as well as significantly more visits from the therapeutic recreation specialist, physiotherapist, occupational therapist, and rehabilitation therapist. The total length of stay in the program was also significantly longer for the rural group $(\mathrm{p}<0.001)$. However, there were no statistically significant differences between the groups according to intensity of rehabilitation received.

When examining baseline scores of all outcome measures, the only significant between-group differences observed were on the FIM ( $p=0.004 ; 95 \% \mathrm{CI},-6.4$ to -1.3 ) as well as the communication domain of the SIS ( $p=0.028 ; 95 \% \mathrm{CI},-8.7$ to -0.52$)$. In both instances, rural residing individuals had higher scores, on average, at baseline than urban clients. There were no significant differences between groups in the ability to make gains on any functional or psychosocial outcome measure between admission to and discharge from the program or between discharge and follow-up.

Rurality of residence did not significantly improve the amount of variance explained in any of the regression analyses. However, before conducting a Bonferroni adjustment, the HADS depression subscale between admission and discharge was found to be significant $\left(\mathrm{p}=0.040, R^{2}\right.$ change: 0.026$)$. In this case, the rurality variable increased the amount of variance explained by $2.6 \%$. Urban residents were able to demonstrate a greater ability to reduce their depression subscale score (mean difference: urban $-1.2 \pm 3.7$ vs rural $-0.5 \pm 3.6$ ), suggesting that there was a greater improvement in depressive symptoms in this cohort during service provision.

\section{DISCUSSION}

CSRTs are an intensive and multidisciplinary stroke rehabilitation service offered in southwestern Ontario for individuals who are unable to access outpatient rehabilitation services or who are believed to benefit more from home-based rehabilitation. Clients living in both rural and urban settings are eligible to receive rehabilitation services via CSRTs. The objective of this study was to compare differences in improvement of poststroke outcomes between urban and rural residing individuals who received services from CSRTs. Findings indicated that both sets of clients experienced improvements in functional and psychosocial outcomes. Encouragingly, there was no evidence to suggest a disparity between the gains made between rural and urban stroke survivors. Our findings provide preliminary evidence that the CSRTs are "leveling the playing field" by providing stroke care in the community regardless of a clients' rurality of residence.

In the literature, there is limited and conflicting evidence regarding differences in stroke recovery between these geographically distinct populations. In a large review comparing urban and rural settings around the world, Joubert et $\mathrm{al}^{8}$ reported that stroke demographics and information on medical care (e.g. stroke incidence, prevalence, mortality, disability, provision of services, management) were extremely variable regardless of a country's level of economic development (i.e. high, medium, or low). Much of the research that does exist has been completed in the United Kingdom, Australia, and United States. Comer and Mueller ${ }^{19}$ compared urban-rural differences on several measures of access to health care in Nebraska in the United States. In contrast, O'Neil et $\mathrm{al}^{20}$ examined provision of stroke resources and outcomes in Scotland in accessible-remote communities (population $<3000$ individuals ${ }^{21}$ ). This research is not particularly applicable to a Canadian context because of large variations in health care system structures and provision of services as well as geographical inconsistencies and varying taxonomies, resulting in diverse definitions of rurality. ${ }^{7}$ Despite this, the current study's 
Table 2: Baseline outcome scores and change in outcome scores between time points (unadjusted analysis)

\begin{tabular}{|c|c|c|c|c|c|c|c|c|c|}
\hline \multirow[t]{2}{*}{ Outcome measure } & \multicolumn{2}{|c|}{ Baseline score } & \multirow[b]{2}{*}{ p value } & \multicolumn{2}{|c|}{ Change (baseline-discharge) } & \multirow[b]{2}{*}{ p value } & \multicolumn{2}{|c|}{ Change (discharge-follow up) } & \multirow[b]{2}{*}{$p$ value } \\
\hline & Urban & Rural & & Urban & Rural & & Urban & Rural & \\
\hline FIM & $104.7(17.7)$ & $108.6(16.4)$ & 0.004 & $5.6(9.2)$ & $5.1(8.4)$ & 0.466 & $0.01(7.1)$ & $0.37(5.1)$ & 0.571 \\
\hline \multicolumn{10}{|l|}{ HADS } \\
\hline Anxiety & $7.2(4.5)$ & $7.3(5.1)$ & 0.942 & $-1.7(4.1)$ & $-1.1(4.1)$ & 0.352 & $-0.2(3.1)$ & $0.1(3.8)$ & 0.633 \\
\hline Depression & $6.6(4.0)$ & $5.9(3.9)$ & 0.223 & $-1.2(3.7)$ & $-0.5(3.6)$ & 0.240 & $-0.3(3.7)$ & $-0.7(2.5)$ & 0.398 \\
\hline Total & $13.0(7.1)$ & $11.5(6.8)$ & 0.093 & $-0.2(5.7)$ & $-0.9(5.2)$ & 0.547 & $-0.4(5.7)$ & $-0.9(5.8)$ & 0.640 \\
\hline RNLI & $15.0(4.7)$ & $16.0(4.1)$ & 0.198 & $2.4(4.4)$ & $2.5(4.2)$ & 0.872 & $0.5(3.9)$ & $1.7(2.4)$ & 0.384 \\
\hline \multicolumn{10}{|l|}{ SIS } \\
\hline Strength & $58.7(27.0)$ & $60.0(24.3)$ & 0.600 & $8.2(20.3)$ & $11.4(19.5)$ & 0.138 & $-3.2(18.8)$ & $-0.8(15.5)$ & 0.310 \\
\hline Memory & $75.9(19.5)$ & $78.9(19.8)$ & 0.121 & $4.3(17.5)$ & $3.8(18.1)$ & 0.783 & $1.0(16.6)$ & $1.1(13.8)$ & 0.942 \\
\hline Communication & $78.1(21.4)$ & $82.8(21.4)$ & 0.028 & $4.2(16.8)$ & $3.2(15.6)$ & 0.562 & $1.3(13.6)$ & $-0.5(13.0)$ & 0.302 \\
\hline ADLs & $66.9(23.8)$ & $69.8(22.2)$ & 0.221 & $7.3(14.8)$ & $5.5(20.4)$ & 0.324 & $0.9(14.4)$ & $0.1(17.0)$ & 0.700 \\
\hline Mobility & $63.2(26.2)$ & $67.8(22.7)$ & 0.063 & $9.4(17.6)$ & $10.4(18.3)$ & 0.583 & $0.2(16.3)$ & $-2.7(12.9)$ & 0.153 \\
\hline Hand Strength & $51.3(37.9)$ & $54.5(36.0)$ & 0.389 & $11.0(24.1)$ & $11.0(19.7)$ & 0.994 & $-3.3(24.9)$ & $0.6(19.6)$ & 0.203 \\
\hline Social participation & $52.1(24.6)$ & $54.7(23.1)$ & 0.272 & $13.8(24.8)$ & $13.7(26.4)$ & 0.966 & $3.8(22.5)$ & $2.9(23.7)$ & 0.770 \\
\hline Physical* & $61.8(23.4)$ & $65.1(20.6)$ & 0.137 & $8.5(13.9)$ & $8.7(13.8)$ & 0.909 & -0.7 (11.6) & $-1.0(9.4)$ & 0.784 \\
\hline
\end{tabular}

$\mathrm{ADL}=$ activities of daily living; FIM = Functional Independence Measure; HAPS $=;$ RNLI = Reintegration to Normal Living Index; SIS $=$ Stroke Impact Scale.

*Physical indicates the composite score of strength, mobility, hand strength, and social participation.

findings are supported by O'Neil et al, ${ }^{20}$ who also found no differences in recovery patterns between the two populations. Overall, there are currently too few studies to offer direct comparisons between our findings from Canada and other countries.

Disparities in health and rehabilitation between rural and urban dwelling individuals remain an important issue throughout Canada and the world. There are a large number of individuals living in population centres with fewer health care supports and services than is typically found in large urban areas. It has been shown that the geographic location where one resides has an association with their health status, personal health behaviours, and health service utilization. ${ }^{22}$ According to a survey of the Canadian population, individuals living in rural communities were less likely to have a general practitioner and had reduced access to specialized medical services than those in urban areas. ${ }^{23}$ Sibley et $\mathrm{al}^{22}$ noted that rural residing individuals tend to delay seeking health care; this is of particular concern given the proportion of rural residents in Canada. The CSRTs aim to bridge this gap in service availability and to facilitate referrals to additional health care resources.

Table 3: Results of multivariate linear regression analyses (adjusted analysis)

\begin{tabular}{|c|c|c|c|c|c|c|}
\hline \multirow[t]{2}{*}{ Outcome measure } & \multicolumn{3}{|c|}{ Admission to discharge } & \multicolumn{3}{|c|}{ Discharge to follow-up } \\
\hline & $\mathbf{N}$ & $R^{2}$ change & p value & $\mathbf{N}$ & $R^{2}$ change & p value \\
\hline FIM & 745 & 0.008 & 0.929 & 480 & 0.678 & 0.411 \\
\hline \multicolumn{7}{|l|}{ HADS } \\
\hline Anxiety & 209 & 0.021 & 0.075 & 112 & 0.000 & 0.962 \\
\hline Depression & 173 & 0.026 & 0.040 & 105 & 0.634 & 0.428 \\
\hline Total & 105 & 0.010 & 0.310 & 141 & 0.009 & 0.349 \\
\hline RNLI & 177 & 0.153 & 0.696 & 61 & 0.044 & 0.834 \\
\hline \multicolumn{7}{|l|}{ SIS } \\
\hline Cognition & 357 & 0.006 & 0.238 & 234 & 0.001 & 0.765 \\
\hline Communication & 357 & 0.003 & 0.408 & 234 & 0.004 & 0.330 \\
\hline Social participation & 357 & 0.000 & 0.775 & 234 & 0.000 & 0.913 \\
\hline Physical* & 357 & 0.000 & 0.819 & 234 & 0.005 & 0.393 \\
\hline
\end{tabular}

FIM = Functional Independence Measure; HAPS = ; RNI = Reintegration to Normal Living Index; SIS = Stroke Impact Scale

*Physical indicates composite score of strength, mobility, hand strength, and social participation. 
Although similar improvements in outcomes were demonstrated between the two groups, rural individuals had slightly higher baseline FIM scores, received significantly more total visits from therapists, and were enrolled in the program for a longer period than their urban counterparts. Although reasons for these findings are speculative, the differences may be due to differential referral practices between urban and rural clients. For example, the CSRT program may have acted as a replacement to inpatient rehabilitation for rural patients who do not live in close proximity to specialized stroke services. Although one may suspect that urban clients could have accessed outpatient based rehabilitation programs to supplement CSRT visits, this is not likely the case because the CSRT program is intended to act as a replacement for traditional outpatient services for those with limited access. Unfortunately, evolving program characteristics make the reason for these differences in baseline characteristics difficult to assess.

It is interesting to note that before correcting for multiple comparisons using the Bonferroni adjustment, urban residents improved more in terms of depressive symptoms than their rural counterparts $(p=0.04)$ from admission to discharge from the program. Although this finding may be due to the higher probability of obtaining false positives with multiple comparisons, the initial significance of the relationship may be important to consider. For example, it has been shown that positive social role functioning (e.g. spending time with friends and family; engaging in social, community, and leisure activities) is associated with a reduction in depressive symptoms poststroke. ${ }^{24} \mathrm{It}$ is possible that many of the urban residents in this study had greater access to additional community programs and were less limited by geographic distance to family, friends, and community-based social activities, resulting in greater opportunities for social participation and inclusion. Future studies should explore the relationship between social participation, depression, and rurality.

\section{Limitations}

Although most of the outcome measures were sufficiently powered to detect a medium effect size, the RNLI outcome measure was not. This was the result of clinicians changing the outcome measure from the SIS midway through the data collection period, resulting in an inadequate sample size. Second, many clients did not meet inclusion criteria due to a number of factors including: (1) this was an administrative dataset and was not collected as rigorously as would be for research purposes; (2) many more clients were assessed for the program than admitted to it; and (3) some clients were lost to the final follow-up. An additional challenge with this analysis is that this is an evolving program. Changes in target lengths of stay, wait times for the program, and client referral practices have occurred over time and are difficult to account for. Finally, the results should be generalized with caution because the data are from a program covering a single geographical area that may differ from other rural areas where distances to health care services may be greater.

\section{ConClusions}

This research aimed to assess the differences in recovery between urban and rural residing stroke survivors, particularly in a Canadian context. Previous research on the CSRT program indicates that this intervention approach has significant positive effects on both physical and psychosocial outcomes of their clients. ${ }^{17}$ The findings of the current analysis further suggest that home-based stroke rehabilitation services benefitted equally both rural- and urban-residing individuals, with no significant differences in improvement between the two groups. This type of poststroke rehabilitation program should be considered in other rural areas where health services are not available or are limited.

\section{Disclosures}

LA, AM, SJ, MR, MM, DU, and RT have nothing to disclose.

\section{Author Contributions}

LA undertook data analysis and interpretation, methods, and an overall review. AM provided discussion and an overall review. SJ wrote the introduction and provided an overall review. MR provided data interpretation, analysis approach, and overall review. MM provided data interpretation and overall review. DU provided clinical interpretation and overall review. RT provided clinical interpretation and overall review.

\section{REFERENCES}

1. Heart and Stroke Foundation. Statistics. 2013. Available from: http:// www heartandstroke com/site/c ikIQLcMWJtE/b 3483991/k 34A8/Statistics.htm, 2013.

2. National Institute of Neurological Disorders and Stroke. Post stroke rehabilitation fact sheet. The large and growing burden of stroke, 2014. Available from: http://stroke.nih.gov/materials/rehabilitation.htm.

3. Patel M, Coshall C, Rudd AG, Wolfe CD. Natural history of cognitive impairment after stroke and factors associated with its recovery. Clin Rehabi. 2003;17:158-66.

4. Good DC, Betterman K, Reichwein RK. Stroke rehabilitation. Continuum (Minneap Minn). 2011;17:545-67.

5. Mayo NE, Wood-Dauphinee S, Cote R, Durcan L, Carelton J. Activity, participation, and quality of life 6 months post stroke. Arch Phys Med Rehabil. 2002;83:1035-42.

6. Teasell R, Foley N, Salter K, Richardson M, Allen L, Hussein N, et al. Evidence-based review of stroke rehabilitation. 16th ed. 2013. Available from: www.ebrsr.com.

7. Jia H, Cowper DC, Tang Y, Litt E, Wilson L. Postacute stroke rehabilitation utilization: are there differences between ruralurban patients and taxonomies? J Rural Health. 2012;28:242-7.

8. Joubert J, Prentice LF, Moulin T, Liaw ST, Jourbert LB, et al. Stroke in rural areas and small communities. Stroke. 2008;39:1920-8.

9. Rodriguez D, Cox M, Zimmer LO, Olson DM, Goldstein LB, Drew L, et al. Similar secondary stroke prevention and medication persistence rates among rural and urban patients. J Rural Health. 2011;27:401-8.

10. Statistics Canada. 2011 census of population. Ottawa, Canada: Statistics Canada, Government of Canada; 2011.

11. Statistics Canada. Structure and change in canada's rural demography: an update to 2006, rural and small town Canada Analysis. Rural Small Town Canada Anal Bull. 2006;7:1.

12. Southwest LHIN. Southwest LHIN facts and FAQs. 2014. Available from: http://southwestlhin.on.ca/Page.aspx?id=1480.

13. Keith RA, Granger CV, Hamilton BB, Sherwin FS. The functional independence measure: a new tool for rehabilitation. Adv Clin Rehabil. 1987;1:6-18.

14. Duncan PW, Wallace D, Studenski S, Lai SM, Johnson D. Conceptualization of a new stroke-specific outcome measure: The Stroke Impact Scale. Top Stroke Rehabil. 2001;8:19-33.

15. Wood-Dauphinee SL, Opzoomer MA, Williams JI, Marchand B, Spitzer WO. Assessment of global function: the Reintegration to Normal Living Index. Arch Phys Med Rehabil. 1988;69:583-90.

16. Zigmond AS, Snaith RP. The hospital anxiety and depression scale. Acta Psychiatrica Scand. 1983;67:361-70. 
17. Allen L, Richardson M, McIntyre A, Janzen S, Meyer M, Ure D, et al. Community stroke rehabilitation teams: providing homebased stroke rehabilitation in Ontario, Canada. Can J Neurol Sci. 2014;41:1-7.

18. Rurality Index for Ontario. RIO postal code look-up. 2008. Available from: https://www.oma.org/PublicApp/nlp/NLPWF003.aspx.

19. Comer J, Mueller K. Access to health care: urban-rural comparisons from a midwestern agricultural state. J Rural Health. 1995;11:128-36.

20. O'Neill NP, Godden DJ. Stroke outcomes in Northern Scotland: does rurality really matter? Rural Remote health. 2003;3:243.

21. Scottish Government Geographic Information Science and Analysis Team. Scottish government urban rural classification 2011-2012. United Kingdom, 2012.
22. Sibley LM, Weiner JP. An evaluation of access to health care services along the rural-urban continuum in Canada. BMC. Health Serv Res. 2011;11:20.

23. DesMeules M, Pong R, Lagace C, Heng D, Manuel D, Pitblado R, et al. How healthy are rural Canadians? An assessment of their health status and health determinants. Public Health Agency of Canada, Ottawa, ON, 2006.

24. Schmid AA, Damush T, Tu W, Bakas T, Kroenke K, Hendrie HC, et al. Depression improvement is related to social role functioning after stroke. Arch Phys Med Rehabil. 2012;93:978-82.

25. Southwest LHIN. Map of the southwest LHIN. Available from: http://www.southwestlhin.on.ca/SiteContent/PublicCommunity/ AboutOurLHIN/Map.aspx. 